\title{
The Role of L-Proline and Co-Catalysts in the Enantioselectivity of OXA-Michael-Henry Reactions
}

\author{
Lucas F. do Carmo, ${ }^{a}$ Simone C. Silva, ${ }^{a}$ Matheus V. Machado, ${ }^{a}$ Paloma S. Prata, ${ }^{\circledR c}$ \\ Alberto Wisniewski Júnior, ${ }^{c}$ Diogo M. Vidal ${ }^{b}$ and José Augusto F. P. Villar ${ }^{\circledR} \varkappa, a$ \\ aLaboratório de Síntese Orgânica e NanoEstruturas, Universidade Federal de São João Del-Rei, \\ Campus Centro-Oeste Dona Lindu, Rua Sebastião Gonçalves Coelho, 400, \\ 35501-296 Divinópolis-MG, Brazil \\ ${ }^{b}$ Universidade Federal de Minas Gerais, Campus Belo Horizonte, \\ Av. Pres. Antônio Carlos, 6627, Pampulha, 31270-901 Belo Horizonte-MG, Brazil \\ ${ }^{c}$ Grupo de Pesquisa em Petróleo e Energia da Biomassa (PEB), Departamento de Química, \\ Universidade Federal de Sergipe, Rodovia Marechal Randon, s/n, Jardim Rosa Elze, \\ 49100-000 São Cristóvão-SE, Brazil
}

\begin{abstract}
The use of L-proline derivatives employed in OXA-Michael-Henry tandem reactions has been an efficient method to produce enantiomerically enriched compounds. In this work it was carried out a study of the OXA-Michael-Henry reactions between salicylaldehyde and $\beta$-nitrostyrenes, catalyzed by L-proline and its derivatives. The corresponding $(R)$-3-nitro-2-phenyl$2 \mathrm{H}$-chromenes were obtained in $55 \%$ enantiomeric excess (ee, $20 \mathrm{~mol} \% \mathrm{~L}$-proline) and $70 \%$ ee (stoichiometric amount) employing $\mathrm{Ti}\left(\mathrm{O}^{i} \mathrm{Pr}\right)_{4}$ as Lewis acid. Despite the ee obtained, to the best of our knowledge, this result represents the highest enantioselectivity obtained in this reaction. Therefore, this work demonstrated that it is possible to obtain considerable enantiomeric excesses in OXA-Michael-Henry reactions using L-proline, an inexpensive and accessible amino acid.
\end{abstract}

Keywords: asymmetric catalysis, L-proline, organocatalysts, OXA-Michael-Henry reactions, co-catalyst

\section{Introduction}

Organocatalysis has been a target of great interest over the past years, due to the ease of obtaining organocatalysts which are easily stored, stable, non-toxic and economical. Additionally, organocatalysis is a class of catalysis that can be performed under mild conditions, without the necessity of inert atmosphere or anhydrous conditions. ${ }^{1-3}$ Nowadays, organocatalysis has shown an exponential increase in the number of publications, expanding the interest in new catalysts and reactions in which asymmetric products can be formed with the use of organocatalysts in classic and useful reactions, such as Diels-Alder, Mannich, Michael reactions, and others. ${ }^{4,5}$

Asymmetric Michael reactions has been widely employed towards the synthesis of chiral compounds in order to develop new synthetic drugs, and to synthesize heterocycles and natural products. ${ }^{6}$ The OXA-Michael-aldol

*e-mail: zevillar@ufsj.edu.br cascade or "tandem" reactions is a series of consecutive intramolecular reactions that occur with the addition of an oxygen atom to an $\alpha, \beta$-unsaturated system, which leads, as a first step, to the formation of an intermediate ion (enolate, nitro-enolate), which in turn performs an aldol addition (or similar) to the carbonyl group present in the initial molecule. ${ }^{7,8}$

Several studies of OXA-Michael-Aldol reactions performed between 2-hydroxyaldehydes and $\alpha, \beta$-unsaturated aldehydes have been developed employing L-proline derivatives, and the results showed excellent enantiomeric excess (ee). ${ }^{9-17}$ In these cases, the $\alpha, \beta$-unsaturated aldehydes were activated through formation of an iminium ion; this being the step of a chiral environment. However, investigation of the reaction of salicylaldehydes with $\beta$-nitrostyrenes (in this case called OXA-Michael-Henry tandem reactions or $\mathrm{OMH}$ ) for asymmetric synthesis of 3-nitro- $2 \mathrm{H}$-chromenes is relatively recent and did not show good enantioselective results when L-proline or L-proline derivatives were employed. ${ }^{15,18-23}$ The 
main results are summarized in the Table 1 . For example, $\mathrm{Xu}$ and co-workers ${ }^{19}$ obtained $85 \%$ ee using $20 \mathrm{~mol} \%$ of a derivative of L-proline $\mathbf{I}$ in the reaction between 4-methoxysalicylaldehyde and $\beta$-nitrostyrene, this being the best result reported for this reaction. Thus, there is great interest on the development of several methods for the synthesis of these compounds, particularly the 3-nitro2-phenyl-2H-chromenes, due to their potential application as pesticides, highly potent antihypertensive drugs and important intermediates in drug synthesis. ${ }^{4}$ Based on the importance of the synthesis of chiral chromenes through $\mathrm{OMH}$ reactions, we disclose herein our synthetic effort for the synthesis of these chiral compounds.

\section{Experimental}

General procedure for the preparation of the racemic 3-nitro2-phenyl-2H-chromene (4)

In a round bottom flask with magnetic stirring salicylaldehyde 2 (2.5 g, $20.5 \mathrm{mmol}), \beta$-nitrostyrene $\mathbf{3}$ $(1.0 \mathrm{~g}, 6.67 \mathrm{mmol})$ and triethylamine $(0.1 \mathrm{~g}, 1.0 \mathrm{mmol})$ were added. The reaction was stirred at room temperature and monitored by thin layer chromatography (TLC). A solid residue was formed, which was removed by filtration in warm ethanol. The solvent of the filtrated was evaporated and the crude product was purified by column chromatography on silica gel eluting with ethyl ether:hexane:dichloromethane $(1: 5: 1)$. The obtained compound was a yellow solid in $69 \%$ yield; mp 89.5-90.5 ${ }^{\circ} \mathrm{C} ;{ }^{1} \mathrm{H} \mathrm{NMR}\left(\mathrm{CDCl}_{3}, 400 \mathrm{MHz}\right) \delta 8.05$ (s, 1H), 7.28-7.39 (m, 7H), 6.99 (td, J 0.8, 7.9 Hz, 1H),

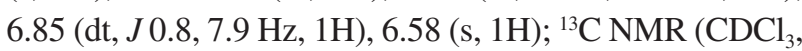
$100 \mathrm{MHz}) \delta 153.68,141.30,136.90,134.43,130.55,129.59$, 129.40, 128.97, 127.14, 122.65, 118.05, 117.40, 74.38; IR (KBr pellets) $v / \mathrm{cm}^{-1} 3074(\mathrm{C}-\mathrm{H}), 1649(\mathrm{C}=\mathrm{C}), 1508$ and $1340\left(\mathrm{NO}_{2}\right), 1493(\mathrm{C}=\mathrm{C})$ aromatic, 1223 and $1121(\mathrm{C}-\mathrm{O}-\mathrm{C})$; high-resolution mass spectrometry (HRMS, electrospray ionization in positive mode (ESI+)) $\mathrm{m} / \mathrm{z}$, calcd. for $\mathrm{C}_{15} \mathrm{H}_{12} \mathrm{NO}_{3}$ $[\mathrm{M}+\mathrm{H}]^{+}:$254.08117; found: 254.08113. The enantiomers were analyzed by high performance liquid chromatography (HPLC) using an Astec Cellulose DMP column (methanol $100 \%)$, retention time $\left(\mathrm{t}_{\mathrm{R}}\right)=11.4 \mathrm{~min}$ isomer $(R)$ and $\mathrm{t}_{\mathrm{R}}=10.5 \min$ isomer $(S)$.

General procedure for the preparation organocatalytic reaction with L-proline and co-catalyst

To a solution of salicylaldehyde $(1.1 \mathrm{mmol})$ it was added $1.5 \mathrm{~mL}$ of appropriated solvent and $20 \mathrm{~mol} \%(0.2 \mathrm{mmol})$ of L-proline. The reaction was stirred at room temperature during $10 \mathrm{~min}$, after that it was added $\beta$-nitrostyrene
(1 mmol), $20 \mathrm{~mol} \%$ of co-catalyst $(0.2 \mathrm{mmol})$ and molecular sieves $4 \AA$. After $120 \mathrm{~h}, 10 \mathrm{~mL}$ of $\mathrm{H}_{2} \mathrm{O}$ and $10 \mathrm{~mL}$ of $\mathrm{HCl}$ $10 \%$ were added to the mixture and extracted with ethyl acetate $(3 \times 30 \mathrm{~mL})$. Organic layer was dried with $\mathrm{Na}_{2} \mathrm{SO}_{4}$ and concentrated under reduced pressure. The product was purified by flash chromatograph on silica column with ethyl ether:hexane:dichloromethane (1:5:1).

\section{3-Nitro-2-phenyl-2H-chromene (4)}

Yellow solid; mp 89.5-90.5 ${ }^{\circ} \mathrm{C} ;{ }^{1} \mathrm{H} \mathrm{NMR}\left(\mathrm{CDCl}_{3}\right.$, $400 \mathrm{MHz}) \delta 8.05(\mathrm{~s}, 1 \mathrm{H}), 7.28-7.39(\mathrm{~m}, 7 \mathrm{H}), 6.99(\mathrm{td}$, $J 0.8,7.9 \mathrm{~Hz}, 1 \mathrm{H}), 6.85(\mathrm{dt}, J 0.8,7.9 \mathrm{~Hz}, 1 \mathrm{H}), 6.58(\mathrm{~s}, 1 \mathrm{H})$; ${ }^{13} \mathrm{C} \mathrm{NMR}\left(\mathrm{CDCl}_{3}, 100 \mathrm{MHz}\right) \delta 153.68,141.30,136.90$, $134.43,130.55,129.59,129.40,128.97,127.14,122.65$, 118.05, 117.40, 74.38; IR (KBr pellets) $v / \mathrm{cm}^{-1} 3074(\mathrm{C}-\mathrm{H})$, $1649(\mathrm{C}=\mathrm{C}), 1508$ and $1340\left(\mathrm{NO}_{2}\right), 1493(\mathrm{C}=\mathrm{C})$ aromatic, 1223 and 1121 (C-O-C); HRMS (ESI+) $\mathrm{m} / z$, calcd. for $\mathrm{C}_{15} \mathrm{H}_{12} \mathrm{NO}_{3}[\mathrm{M}+\mathrm{H}]^{+}$: 254.08117; found: 254.08113; $[\alpha]_{\mathrm{D}}+16.3\left(c 0.05 \mathrm{~g} \mathrm{~mL}^{-1}\right.$ in $\left.\mathrm{CHCl}_{3}\right)$. The enantiomers were analyzed by HPLC using an Astec Cellulose DMP column (methanol 100\%), major enantiomer: $t_{R}=11.4$ min, minor enantiomer: $\mathrm{t}_{\mathrm{R}}=10.5 \mathrm{~min}$.

\section{3-Nitro-2-(4-chlorophenyl)-2H-chromene (4a)}

Yellow solid; mp 134.5-135.5 ${ }^{\circ} \mathrm{C}$; ${ }^{1} \mathrm{H}$ NMR $\left(\mathrm{CDCl}_{3}\right.$, $200 \mathrm{MHz}) \delta 8.05(\mathrm{~s}, 1 \mathrm{H}), 7.28-7.38(\mathrm{~m}, 6 \mathrm{H}), 7.01(\mathrm{td}$, $J$ 1.1, $7.8 \mathrm{~Hz}, 1 \mathrm{H}), 6.85$ (dt, J 1.1, $7.8 \mathrm{~Hz}, 1 \mathrm{H}), 6.54$ (s, $1 \mathrm{H}) ;{ }^{13} \mathrm{C} \mathrm{NMR}\left(\mathrm{CDCl}_{3}, 50 \mathrm{MHz}\right) \delta 153.46,141.01,135.60$, 135.46, 134.61, 130.64, 129.56, 129.23, 128.56, 122.90, 117.96, 117.44, 73.67; IR (KBr pellets) $v / \mathrm{cm}^{-1} 3080$ $(\mathrm{C}-\mathrm{H}), 1639$ and $1605(\mathrm{C}=\mathrm{C}), 1501$ and $1330\left(\mathrm{NO}_{2}\right), 1487$ $(\mathrm{C}=\mathrm{C})$ aromatic, 1225 and $1121(\mathrm{C}-\mathrm{O}-\mathrm{C})$; HRMS (ESI+) $m / z$, calcd. for $\mathrm{C}_{15} \mathrm{H}_{11} \mathrm{ClNO}_{3}[\mathrm{M}+\mathrm{H}]^{+}: 288.04220$; found: 288.04203. The enantiomers were analyzed by HPLC using an Astec Cellulose DMP column (methanol 100\%), major enantiomer: $t_{R}=12.09$ min, minor enantiomer: $\mathrm{t}_{\mathrm{R}}=11.78 \mathrm{~min}$.

\section{3-Nitro-2-(4-bromophenyl)-2H-chromene (4b)}

Yellow solid; mp $146-147{ }^{\circ} \mathrm{C}$; ${ }^{1} \mathrm{H}$ NMR $\left(\mathrm{CDCl}_{3}\right.$, $400 \mathrm{MHz}) \delta 8.05(\mathrm{~s}, 1 \mathrm{H}), 7.44(\mathrm{~d}, J 8.4 \mathrm{~Hz}, 2 \mathrm{H}), 7.30-7.36$ $(\mathrm{m}, 2 \mathrm{H}), 7.21-7.26(\mathrm{~m}, 2 \mathrm{H}), 7.01(\mathrm{t}, 7.5 \mathrm{~Hz}, 1 \mathrm{H}), 6.86(\mathrm{~d}$, $J 8.4 \mathrm{~Hz}, 1 \mathrm{H}), 6.53(\mathrm{~s}, 1 \mathrm{H}) ;{ }^{13} \mathrm{C} \mathrm{NMR}\left(\mathrm{CDCl}_{3}, 50 \mathrm{MHz}\right)$ $\delta 153.30,140.79,135.80,134.49,132.06,130.52,129.48$, 128.70, 123.69, 122.79, 117.81, 117.31, 73.57; IR (KBr pellets) $\mathrm{v} / \mathrm{cm}^{-1} 567(=\mathrm{C}-\mathrm{H}), 574(\mathrm{C}-\mathrm{Br}), 852$ (aromatic p-), 960 (=C-H aromatic), $1066(\mathrm{C}-\mathrm{O}), 1327$ and 1502 $\left(\mathrm{NO}_{2}\right), 1346$ and $3082(\mathrm{C}-\mathrm{H}), 1639$ and $3367(\mathrm{C}=\mathrm{C})$; HRMS (ESI+) $m / z$, calcd. for $\mathrm{C}_{15} \mathrm{H}_{11} \mathrm{BrNO}_{3}[\mathrm{M}+\mathrm{H}]^{+}$: 331.99169; found: 331.99146. The enantiomers were analyzed by HPLC using an Astec Cellulose DMP column 
Table 1. Best conditions of literature results of $\mathrm{OMH}$ reactions with L-proline derivatives

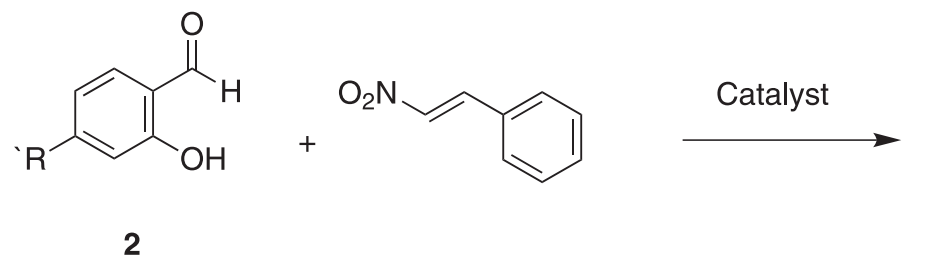

$$
\mathrm{R}^{\prime}=\mathrm{OMe} \text { or } \mathrm{H} \quad \mathrm{R}^{\prime}=\text { OMe or } \mathrm{H}
$$

\begin{tabular}{lccc}
\hline Catalyst & Yield /\% & Enantiomeric excess (ee) $/ \%$ & Refer \\
\hline 1 & 13 & & 0 \\
2 & & 67 & 85
\end{tabular}

3<smiles>c1cc(C2CN(C[C@@H]3CCCN3)N=N2)nc(C2CN(C[C@@H]3CCCN3)N=N2)c1</smiles><smiles>O=C(O)[C@H]1CCCCN1</smiles>
$\mathrm{HO}$<smiles>O=C([C@@H]1C[C@@H](O)CN1)N1CCOCC1</smiles>

V

7<smiles>C=CC1CN2CCC1C2[C@H](NC(=S)Nc1cc(C(F)(F)F)cc(C(F)(F)F)c1)c1ccnc2ccc(OC)cc12</smiles> 
(methanol 100\%), major enantiomer: $\mathrm{t}_{\mathrm{R}}=12.75 \mathrm{~min}$, minor enantiomer: $\mathrm{t}_{\mathrm{R}}=12.59 \mathrm{~min}$.

\section{3-Nitro-2-(4-methoxyphenyl)-2H-chromene (4c)}

Yellow solid; mp $155-156{ }^{\circ} \mathrm{C} ;{ }^{1} \mathrm{H}$ NMR $\left(\mathrm{CDCl}_{3}\right.$, $200 \mathrm{MHz}) \delta 8.05(\mathrm{~s}, 1 \mathrm{H}), 7.23-7.36(\mathrm{~m}, 4 \mathrm{H}), 6.98-7.03$ (m, 1H), 6.78-6.88 (m, 3H), $6.52(\mathrm{~s}, 1 \mathrm{H}), 3.76(\mathrm{~s}, 3 \mathrm{H})$; ${ }^{13} \mathrm{C}$ NMR $\left(\mathrm{CDCl}_{3}, 50 \mathrm{MHz}\right) \delta 160.58,153.64,141.48$, $134.33,130.45,129.13,128.65,122.54,118.13,117.45$, 114.30, 74.10, 55.37; IR ( $\mathrm{KBr}$ pellets) $\mathrm{v} / \mathrm{cm}^{-1} 794$ $(=\mathrm{C}-\mathrm{H}), 852$ (aromatic $p$-), $1257(\mathrm{C}-\mathrm{O}), 1328$ and 1510 $\left(\mathrm{NO}_{2}\right), 2904(\mathrm{C}-\mathrm{H}), 1639$ and $1647(\mathrm{C}=\mathrm{C})$; HRMS (ESI+) $m / z$, calcd. for $\mathrm{C}_{16} \mathrm{H}_{13} \mathrm{NO}_{4}[\mathrm{M}+\mathrm{Na}]^{+}$: 306.07368; found: 306.07365. The enantiomers were analyzed by HPLC using an Astec Cellulose DMP column (methanol 100\%), major enantiomer: $t_{R}=11.99$ min, minor enantiomer: $\mathrm{t}_{\mathrm{R}}=11.34 \mathrm{~min}$.

\section{3-Nitro-2-(4-fluorophenyl)-2H-chromene (4d)}

Yellow solid; mp 97.5-99.5 ${ }^{\circ} \mathrm{C} ;{ }^{1} \mathrm{H}$ NMR $\left(\mathrm{CDCl}_{3}\right.$, $200 \mathrm{MHz}) \delta 8.05(\mathrm{~s}, 1 \mathrm{H}), 7.28-7.40(\mathrm{~m}, 4 \mathrm{H}), 6.95-7.05$ $(\mathrm{m}, 3 \mathrm{H}), 6.86(\mathrm{~d}, J 8.5 \mathrm{~Hz}, 1 \mathrm{H}), 6.55(\mathrm{~s}, 1 \mathrm{H}) ;{ }^{13} \mathrm{C} \mathrm{NMR}$ $\left(\mathrm{CDCl}_{3}, 50 \mathrm{MHz}\right) \delta[164.66,162.19(\mathrm{~d}, J 248.9 \mathrm{~Hz})]$, 153.47, 141.21, 134.57, [132.91, $132.87(\mathrm{~d}, J 3.2 \mathrm{~Hz})$, 130.60, 129.45, [129.17, 129.08 (d, J 8.5 Hz)], 122.82, 117.96, 117.44, [116.11, 115.89 (d, J 21.7 Hz)], 73.70; IR (KBr pellets) $v / \mathrm{cm}^{-1} 3067(\mathrm{C}-\mathrm{H}), 1651$ and $1603(\mathrm{C}=\mathrm{C})$, 1519 and $1340\left(\mathrm{NO}_{2}\right), 1503(\mathrm{C}=\mathrm{C})$ aromatic, 1219 and 1119 (C-O-C); HRMS (ESI+) $\mathrm{m} / z$, calcd. for $\mathrm{C}_{15} \mathrm{H}_{11} \mathrm{FNO}_{3}$ $[\mathrm{M}+\mathrm{H}]^{+}:$272.07175; found: 272.07157 . The enantiomers were analyzed by HPLC using an Astec Cellulose DMP column (methanol 100\%), major enantiomer: $t_{R}=10.78$ min, minor enantiomer: $t_{R}=10.35$ min.

3-Nitro-2-(2,3-dichlorophenyl)-2H-chromene (4e)

Yellow solid; mp 158.5-159.5 ${ }^{\circ} \mathrm{C}$; ${ }^{1} \mathrm{H}$ NMR $\left(\mathrm{CDCl}_{3}\right.$,
$200 \mathrm{MHz}) \delta 8.16$ (s, 1H), 7.26-7.5 (m, 3H), 6.96-7.14 (m, $4 \mathrm{H}), 6.83(\mathrm{~d}, J 7.8 \mathrm{~Hz}, 1 \mathrm{H}) ;{ }^{13} \mathrm{C} \mathrm{NMR}\left(\mathrm{CDCl}_{3}, 50 \mathrm{MHz}\right)$ $\delta 152.97,139.88,135.44,134.57,131.64,130.37$, 127.40, 126.03, 122.80, 117.53, 117.44, 71.26; IR ( KBr pellets) $v / \mathrm{cm}^{-1} 3074(\mathrm{C}-\mathrm{H}), 1651$ and $1602(\mathrm{C}=\mathrm{C}), 1508$ $(\mathrm{C}=\mathrm{C})$ aromatic, $1340\left(\mathrm{NO}_{2}\right), 1223$ and $1119(\mathrm{C}-\mathrm{O}-\mathrm{C})$; HRMS (ESI+) $\mathrm{m} / z$, calcd. for $\mathrm{C}_{15} \mathrm{H}_{10} \mathrm{Cl}_{2} \mathrm{NO}_{3}[\mathrm{M}+\mathrm{H}]^{+}$: 322.00323; found: 322.00323 . The enantiomers were analyzed by HPLC using an Astec Cellulose DMP column (methanol 100\%), major enantiomer: $t_{R}=10.90 \mathrm{~min}$, minor enantiomer: $t_{R}=11.65$ min.

\section{Results and Discussion}

Starting with the synthesis of the racemic 3-nitro2-phenyl-2H-chromene (4) under conditions described by Sakakibara et al. ${ }^{24}$ triethylamine was applied as base and the reaction between salicylaldehyde (2) and $\beta$-nitrostyrene (3) at room temperature and solvent free furnished $\mathbf{4}$ in 69\% yield (Figure 1).

As the chiral catalyst species are required to create a chiral environment, ${ }^{4}$ L-proline was initially used as an organocatalyst to understand the scope and limitations of this reaction (Table 1). To promote the best conditions for the $\mathrm{OMH}$ reactions and to evaluate the catalytic potential and asymmetric induction of the catalyst, this reaction was carried out under different conditions. Firstly, $20 \mathrm{~mol} \%$ of L-proline and $4 \AA$ molecular sieves were used under solvent-free conditions to induce the OMH reactions. Surprisingly, the desired product was obtained with $51 \%$ yield and $14 \%$ ee (Table 2, entry 1 ). In contrast to literature reports, which have indicated no ee when employing L-proline, ${ }^{19}$ this result opens the possibility of developing a chiral $\mathrm{OMH}$ reaction. Subsequently, by using different solvents, the effects on ee were evaluated, and the best results were obtained using non-polar solvents such as<smiles>O=Cc1ccccc1O</smiles><smiles>O=[N+]([O-])C=Cc1ccccc1</smiles>

3

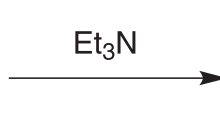<smiles>CC=COCCc1ccccc1</smiles>

(S)-3-Nitro-2H-chromene
4<smiles>O=[N+]([O-])C1=Cc2ccccc2OC1c1ccccc1</smiles>

(R)-3-Nitro-2H-chromene
2

$1500 \frac{1}{12000-13}$

(1) 
toluene and chloroform (Table 2, entries 2-4). However, the best yields were obtained by employing polar protic solvents, although the proportion of ee remained relatively low, which would become better with increasing steric hindrance of the solvent (Table 2, entries 5-7).

Subsequently, the OMH reaction between $\mathbf{2}$ and $\mathbf{3}$ in the presence of $20 \mathrm{~mol} \%$ of L-proline using different cocatalysts (Figure 2) was also investigated, based on previous literature reports. ${ }^{4}$

The presence of L-tartaric acid (A) improved the asymmetric environment when compared to the conditions without co-catalyst, with or without solvent. According to Table 2, the $\mathrm{OMH}$ reactions in the presence of $\mathbf{A}$, using toluene as solvent, increased the proportion of ee to $42 \%$ (Table 2, entry 9); clearly a better result when compared to the conditions without co-catalyst (Table 2, entry 2, $25 \%$ ee).

The influence of temperature on variation of ee was also evaluated, showing lower ee when the reaction was performed at $80^{\circ} \mathrm{C}$ with co-catalyst $\mathbf{A}$ (Table 2, entry 10 , $25 \%$ ee), when compared with room temperature condition (Table 2, entry 8,30\% ee).

Polar protic solvents such as dimethyl sulfoxide (DMSO) and dimethylformamide (DMF) decreased the ee values, indicating that the interactions between acid hydrogens from $\mathbf{A}$ and $\beta$-nitrostyrene might be directly affected by decreasing bonding intensity affecting the chiral environment. Therefore, as shown in Table 2, the reaction did not result in considerable enantioselectivity when DMSO or DMF were used as solvent (Table 2, entries $11,12,15$ and 18).

Protic polar solvents showed lower enantioselectivity, possibly due to their capacity to interact with the organocatalyst and L-proline by hydrogen bonding, disfavoring the formation of the iminium and interactions with the nitro group. On the other hand, non-polar solvents such as toluene and chloroform increased the chiral environment, allowing the best asymmetric performance in the proposed reaction. ${ }^{23}$

The use of co-catalyst $\mathbf{A}$ allowed better ee on formation of 4; therefore, it was decided to evaluate the enantioselectivity of the reactions using other co-catalysts that had been shown to be efficient for organocatalysis. ${ }^{25}$

When co-catalysts $\mathbf{B}$ and $\mathbf{C}$ were used, poor enantioselectivities were observed, the condition with toluene showing the best results (Table 2, entries 16 and 19, 14 and $8 \%$, respectively). Xu and co-workers ${ }^{19}$ explain the success of co-catalyst $\mathbf{B}$ possibly by a dual performance in the process with the formation of the aromatic iminium and hydrogen-bonding interaction between the oxygen of the nitro group and phenolic hydrogen of $\mathbf{B}$.
A<smiles>O=C(O)C(O)C(O)C(=O)O</smiles>

L(+)-Tartaric acid

D<smiles></smiles>

Titanium tetraisopropoxide

G<smiles>Nc1ccc([N+](=O)[O-])cc1</smiles>

p-Nitro-Aniline
B<smiles>O=C(O)c1ccccc1O</smiles>

Salicylic acid

E<smiles>Oc1ccc2ccccc2c1-c1c(O)ccc2ccccc12</smiles>

$(R)-(+)$-Binol

H<smiles>CCOCC</smiles>

Borotrifluoride
C<smiles>O=C(O)c1ccccc1</smiles>

Benzoic acid

$\mathbf{F}$<smiles>Oc1ccc2ccccc2c1-c1c(O)ccc2ccccc12</smiles>

(S)-(-)-Binol

Figure 2. Co-catalysts used in OXA-Michael-Henry reactions. 
Table 2. Results of OMH reactions with L-proline<smiles>O=Cc1ccccc1O</smiles>

1

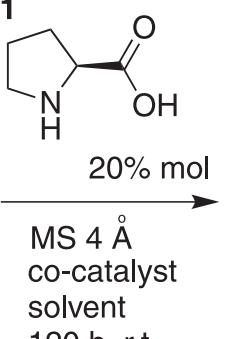<smiles>O=[N+]([O-])C1=Cc2ccccc2O[C@H]1c1ccccc1</smiles>

4 2 3 120 h, r.t. Yield ${ }^{\mathrm{b}} /$

60

67

$65^{\mathrm{d}}$

84

78

73

67

58

$65^{\mathrm{e}}$

62

57

78

65

56

65

80

60

72

83

59

69

62

58

70

58

85

80

75

52

52

54

50
Enantiomeric excess (ee) / \% $14(R)$

$25(R)$

$30(R)$

$30(R)$

$8(R)$

$12(R)$

$16(R)$

$30(R)$

$42(R)$

$25(R)$

0

0

$16(R)$

$24(R)$

0

$14(R)$

$6(R)$

0

$8(R)$

$4(R)$

$55(R)$

$27(R)$

$50(R)$

$50(R)$

$30(R)$

$40(R)$

$11(R)$

$17(R)$

$18(R)$

$35(R)$

$35(R)$

$30(R)$

$28(R)$ 
The influence of Lewis acids in this organocatalysis was also investigated, since they have shown promising results. ${ }^{26}$ In this context, the use of $\operatorname{Ti}\left(\mathrm{O}^{i} \mathrm{Pr}\right)_{4}(\mathbf{D})$ and $\mathrm{BF}_{3} \cdot \mathrm{EtO}_{2}(\mathbf{H})$ were evaluated under different conditions (Table 2, entries 21-29 and 33).

In the presence of $\mathbf{D}$, the enantioselectivity was increased considerably: 55\% ee with toluene (Table 2, entry 21) and $27 \%$ ee with $\mathrm{CHCl}_{3}$ (Table 2, entry 22). However, a decrease in ee was observed when co-catalyst $\mathbf{H}$ was employed.

In the presence of other co-catalysts, such as $\mathbf{E}$ and the mixtures $\mathbf{A} / \mathbf{D}, \mathbf{D} / \mathbf{E}$, and $\mathbf{D} / \mathbf{F}$ (in the ratio of 1:1) (Table 2, entries 23-26), the efficiency of ee was reduced when compared to co-catalyst $\mathbf{D}$, possibly due to the interactions between both co-catalysts, thus decreasing the interactions with salicylaldehyde and $\beta$-nitrostyrene.

Entries 30-33 of Table 2 show the screening of alternative co-catalysts $(\mathbf{E}-\mathbf{H})$ in toluene, as this solvent showed the best results in the previous experiments. These conditions resulted in moderate ee excesses and lower yields when compared to the reactions with $\mathbf{D}$ as co-catalyst.

Chiral binol in association with $\operatorname{Ti}\left(\mathrm{O}^{i} \mathrm{Pr}\right)_{4}$ were applied by $\mathrm{Pu}$ and co-workers ${ }^{27}$ in highly enantioselective addition of alkynes to aldehydes. Based on these results, we decided to associate $(R)$ - and $(S)$-binol to increase the chiral environment. ${ }^{26,27}$ Therefore, such association could be appropriate when comparing the results obtained in this work, since the use of the co-catalyst $\mathbf{D}$ demonstrated the most promising results. These results are probably due to the action of $\mathbf{D}$ as a Lewis acid, interacting with the nitro group in a more expressive way when compared to other co-catalysts.

Thus, the best enantioselectivity was seen in reactions using D only, compared to the use of $(R)$-binol $(\mathbf{E})$ and $(S)$-binol (F) (Table 2, entries 30 and 31, 35\% ee), or to a mixture of co-catalysts $\mathbf{D} / \mathbf{E}$ or $\mathbf{D} / \mathbf{F}$ (Table 2, entries 23 and $24,50 \%$ ee). These results support that the chiral induction is promoted only by L-proline.

These results are considered satisfactory when compared with the results previously reported using L-proline as organocatalyst. ${ }^{19}$ For example, Karthikeyan and Sankararaman ${ }^{20}$ carried out the reaction using L-proline derivatives in DMF, $\mathbf{4}$ was obtained in low yields and with a maximum ee of $24 \%$.

Some additional information of the limitations of this reaction needs to be discussed. First, the use of organic $\left(\mathrm{Et}_{3} \mathrm{~N}\right)$ or inorganic $\left(\mathrm{K}_{2} \mathrm{CO}_{3}\right)$ bases to promote the deprotonation of phenolic hydrogen furnished the desired product, but no ee were observed. These results indicated that there is no formation of iminium salt, but occurs the direct attack of phenolate to $\beta$-nitrostyrene. Second, the reaction does not depend on the time to formation of iminium salt, reactions performed with more reaction time between salicylaldehyde and L-proline furnished the same results and without L-proline did not form the desired product.

Having established the best reaction conditions, as well as the organocatalyst that demonstrated better enantioselectivity, a range of $\beta$-nitrostyrene derivatives (3a-3e) was investigated to evaluate the versatility of the mediated system developed (Table 3, entries 1-5). All the five proposed reactions resulted in considerable enantioselectivity, with the best result being achieved with $\beta$-nitrostyrene 3e (Table 3, entry 5, 42\% ee). However, the presence of substituents did not improve the enantioselectivity when compared to unsubstituted $\beta$-nitrostyrene $\mathbf{3}$ as substrate (Table 2, entry 21). ${ }^{28}$

The role of the L-proline derivatives $\mathbf{1 a}, \mathbf{1 b}$ and $\mathbf{1 c}$ as catalysts was also investigated (Figure 3 ). The assays employing 1a, $\mathbf{1 b}$ and $\mathbf{1 c}$ were carried out under similar conditions to those used with L-proline, and the results are summarized in Table 4.

Initially, the derivatives of L-proline were assayed, under established conditions, without the presence of co-catalyst. The entries 1-6 show the formation of product 4 in moderate yields. When diethyl-L-proline (1a) (entries 1 and 4) was used, the reactions did not show enantioselectivity, due to the impossibility of iminium formation. Reactions using derivatives $\mathbf{1 b}$ (entries 2-5) and 1c (entries 3-6), afforded 30 and $53 \%$ ee, respectively, showing the influence of co-catalyst $\mathbf{D}\left(\mathrm{Ti}\left(\mathrm{O}^{i} \mathrm{Pr}\right)_{4}\right)$ forming an effective interaction between nitro group and iminium salt.

Regarding the best result of ee employing L-proline and the co-catalyst $\mathbf{D}$, both with $20 \mathrm{~mol} \%$ (Table 2, entry 21 , $55 \%$ ee), we decided to evaluate the effect of different molar ratios of L-proline and the co-catalyst $\mathbf{D}$ (Table 5). Increasing the quantity of L-proline to equimolar ratio led to a low increase in enantioselectivity (Table 5, entry 2, $33 \%$ ee). On the other hand, an increase of L-proline quantity with the concentration of the co-catalyst $\mathbf{D}$ remaining in $20 \mathrm{~mol} \%$ did not affect the ee. Moreover, increasing both L-proline and the co-catalyst $\mathbf{D}$ to equimolar ratio, furnished the desired product with $70 \%$ ee, whereas a decrease in L-proline amount to $20 \mathrm{~mol} \%$ affected the rate of reaction and ee (Table 5, entries 5 and 6). This result shows the direct influence of $\operatorname{Ti}\left(\mathrm{O}^{i} \mathrm{Pr}\right)_{4}$ concentration and L-proline amount on the product yield and ee. These observations suggest an interaction between these two reagents and that, decreasing the L-proline quantity and increasing the $\mathrm{Ti}\left(\mathrm{O}^{i} \mathrm{Pr}\right)_{4}$ concentration might not provide free L-proline to produce the iminium salt with salicylaldehyde. 
Table 3. Results of OMH reactions between L-proline with chromene derivatives $\mathbf{4 a - 4 e}$<smiles>[R]c1ccc(/C=C/[N+](=O)[O-])c([R])c1[R]</smiles>

2

3a: $\mathrm{R}^{3}=\mathrm{Cl}$, 3b: $\mathrm{R}^{3}=\mathrm{Br}$ 3c: $R^{3}=O M e, 3 d: R_{3}=F$ 3e : $R^{1}, R^{2}=2,3$ di-chloro

1

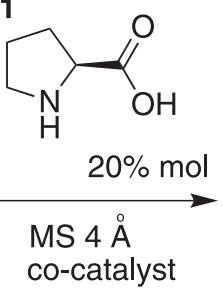

Toluene 120 h, r.t.<smiles>[R]c1ccc([C@H]2Oc3ccccc3C=C2[N+](=O)[O-])c([R])c1[R]</smiles>

4a: $\mathrm{R}^{3}=\mathrm{Cl}, \mathbf{4 b}: \mathrm{R}^{3}=\mathrm{Br}$

4c: $R^{3}=$ OMe, 4d: $R^{3}=F$

$4 e: R^{1} R^{2}=2,3$ di-chloro

\begin{tabular}{lccc}
\hline entry & Chromene & Yield $/ \%^{\mathrm{a}} \%$ & ${\text { Enantiomeric excess }(\text { ee })^{\mathrm{b}} / \%}^{\circ}$ \\
\hline 1 & $\mathbf{4 a}$ & 58 & $33(R)$ \\
2 & $\mathbf{4 b}$ & 52 & $28(R)$ \\
3 & $\mathbf{4 c}$ & 48 & $25(R)$ \\
4 & $\mathbf{4 d}$ & 64 & $35(R)$ \\
5 & $\mathbf{4 e}$ & 58 & $42(R)$ \\
\hline
\end{tabular}

${ }^{a}$ The product formation was monitored by HPLC (C18 column, MeOH: $\mathrm{H}_{2} \mathrm{O}$ 80:20); bee was determined by HPLC chiral cellulose column (100\% MeOH).<smiles>CCOC(=O)C1CCCN1CC</smiles>

1a Diethy-L-proline

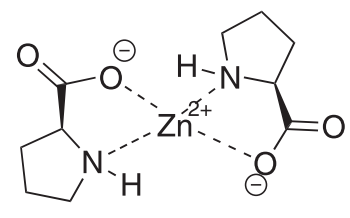

1b $\quad \mathrm{Zn}[\mathrm{L}-\text { proline }]_{2}$<smiles>OCC1CCCN1</smiles>

$1 c$ L-prolinol

Figure 3. Derivatives of L-proline 1a, $\mathbf{1 b}$ and $\mathbf{1 c}$.

Table 4. Results of OMH employing L-proline derivatives<smiles>O=Cc1ccccc1O</smiles>

2

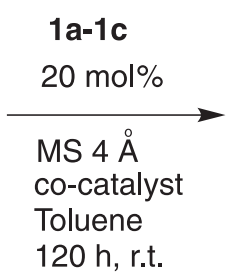<smiles>O=[N+]([O-])C1=Cc2ccccc2O[C@H]1c1ccccc1</smiles>

4

\begin{tabular}{|c|c|c|c|c|}
\hline entry & Derivative & Co-catalyst & Yield $^{a} \%$ & Enantiomeric excess (ee $)^{\mathrm{b}} / \%$ \\
\hline 1 & $1 \mathrm{a}$ & - & 56 & 0 \\
\hline 2 & $1 \mathrm{~b}$ & - & 35 & 0 \\
\hline 3 & $1 \mathrm{c}$ & - & 16 & 0 \\
\hline 4 & $1 \mathrm{a}^{\mathrm{c}}$ & $\mathrm{Ti}\left(\mathrm{O}^{\prime} \mathrm{Pr}\right)_{4}$ & 58 & 0 \\
\hline 5 & $1 b^{c}$ & $\mathrm{Ti}\left(\mathrm{O}^{\prime} \mathrm{Pr}\right)_{4}$ & 39 & $30(R)$ \\
\hline 6 & $1 \mathrm{c}^{\mathrm{c}}$ & $\mathrm{Ti}\left(\mathrm{O}^{\prime} \mathrm{Pr}\right)_{4}$ & 18 & $53(R)$ \\
\hline
\end{tabular}

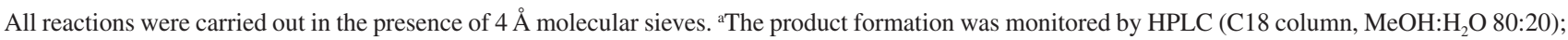
bee was determined by HPLC chiral cellulose column (100\% MeOH); ${ }^{c} 20 \mathrm{~mol} \% \mathrm{Ti}\left(\mathrm{O}^{\mathrm{i}} \mathrm{Pr}\right)_{4}$ (co-catalyst). 
Table 5. Results of the $\mathrm{OMH}$ reactions with different concentrations of L-proline and $\mathrm{Ti}\left(\mathrm{O}^{i} \mathrm{Pr}\right)_{4}$<smiles>O=Cc1ccccc1O</smiles>

2<smiles>O=[N+]([O-])C=Cc1ccccc1</smiles>

3
1

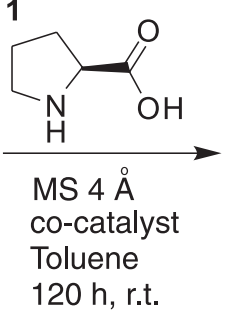<smiles>O=[N+]([O-])C1=Cc2ccccc2O[C@H]1c1ccccc1</smiles>

4

\begin{tabular}{lcccc}
\hline entry & L-Proline $/ \%$ & $\mathrm{Ti}\left(\mathrm{O}^{i} \mathrm{Pr}\right)_{4} / \%$ & Yield $^{\mathrm{a}} / \%$ & ${\text { Enantiomeric excess }(\mathrm{ee})^{\mathrm{b}} / \%}^{\circ}$ \\
\hline $1^{\mathrm{c}}$ & 20 & - & 60 & $56(R)$ \\
2 & 100 & - & 56 & $33(R)$ \\
$3^{\mathrm{d}}$ & 20 & 20 & 59 & $55(R)$ \\
4 & 100 & 20 & 59 & $55(R)$ \\
5 & 100 & 100 & 54 & $70(R)^{\mathrm{e}}$ \\
6 & 20 & 100 & 35 & $40(R)$ \\
\hline
\end{tabular}

aThe product formation was monitored by HPLC (C18 column, MeOH: $\mathrm{H}_{2} \mathrm{O}$ 80:20); bee was determined by HPLC chiral cellulose column (100\% MeOH); 'Table 2, entry 2; ' Table 2, entry 21 ; esimilar result was observed with $\mathrm{CHCl}_{3}$ as solvent.

Although the synthesis of nitrochromene through the reaction of salicylaldehyde with $\beta$-nitrostyrene is not performed under catalytic conditions, we further investigated the reaction with the different $\beta$-nitrostyrenes in equimolar proportion (Table 6, entries 1-5).

In all cases we observed an increase in ee and a decrease in reaction yield, corroborating the direct influence of L-proline and $\operatorname{Ti}\left(\mathrm{O}^{i} \mathrm{Pr}\right)_{4}$ on reaction rate and ee.

In an attempt to explain the process of chiral asymmetry transfer, we proposed the addition of the favored $E$-iminium (EI) to the $\mathrm{Si}$ face of $\beta$-nitrostyrene, leading to the observed
$R$ products (Figure 4). The use of $\operatorname{Ti}\left(\mathrm{O}^{i} \mathrm{Pr}\right)_{4}$ is essential to create an involvement between iminium adduct EI and $\beta$-nitrostyrene (TS-Ti). ${ }^{29}$

\section{Conclusions}

This work showed that reactions using L-proline, a low cost and easily obtainable reagent, performed under mild conditions, are an efficient method for the preparation of chromenes based on OXA-Michael-Henry reactions with up to $70 \%$ ee employing stoichiometric amounts

Table 6. Results of OMH reactions with stoichiometric L-proline with chromene derivatives 4a-4e<smiles>[R]c1ccc(/C=C/[N+](=O)[O-])c([R])c1[R]</smiles>

2
3a: $\mathrm{R}^{3}=\mathrm{Cl}, \mathbf{3 b}: \mathrm{R}^{3}=\mathrm{Br}$
3c: $R^{3}=O M e, 3 d: R_{3}=F$
3e : $R^{1}, R^{2}=2,3$ di-chloro

1

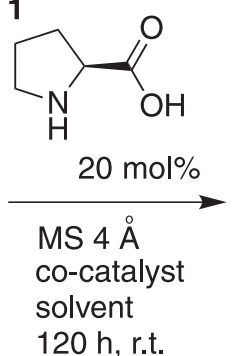<smiles>[R]c1ccc([C@@H]2Oc3ccccc3C=C2[N+](=O)[O-])c([R])c1</smiles>

4a: $\mathrm{R}^{3}=\mathrm{Cl}, \mathbf{4 b}: \mathrm{R}^{3}=\mathrm{Br}$

4c: $R^{3}=O M e, 4 d: R^{3}=F$ $4 e: R^{1} R^{2}=2,3$ di-chloro

\begin{tabular}{|c|c|c|c|}
\hline entry & Chromene & Yield $^{\mathrm{a}} / \%$ & Enantiomeric excess $(\mathrm{ee})^{\mathrm{b}} / \%$ \\
\hline 1 & $4 a$ & 31 & $60(R)$ \\
\hline 2 & $4 b$ & 34 & $50(R)$ \\
\hline 3 & $4 c$ & 23 & $70(R)$ \\
\hline 4 & 4d & 37 & $61(R)$ \\
\hline 5 & $4 e$ & 40 & $57(R)$ \\
\hline
\end{tabular}

${ }^{a}$ The product formation was monitored by HPLC (C18 column, MeOH: $\mathrm{H}_{2} \mathrm{O}$ 80:20); bee was determined by HPLC chiral cellulose column (100\% MeOH). 


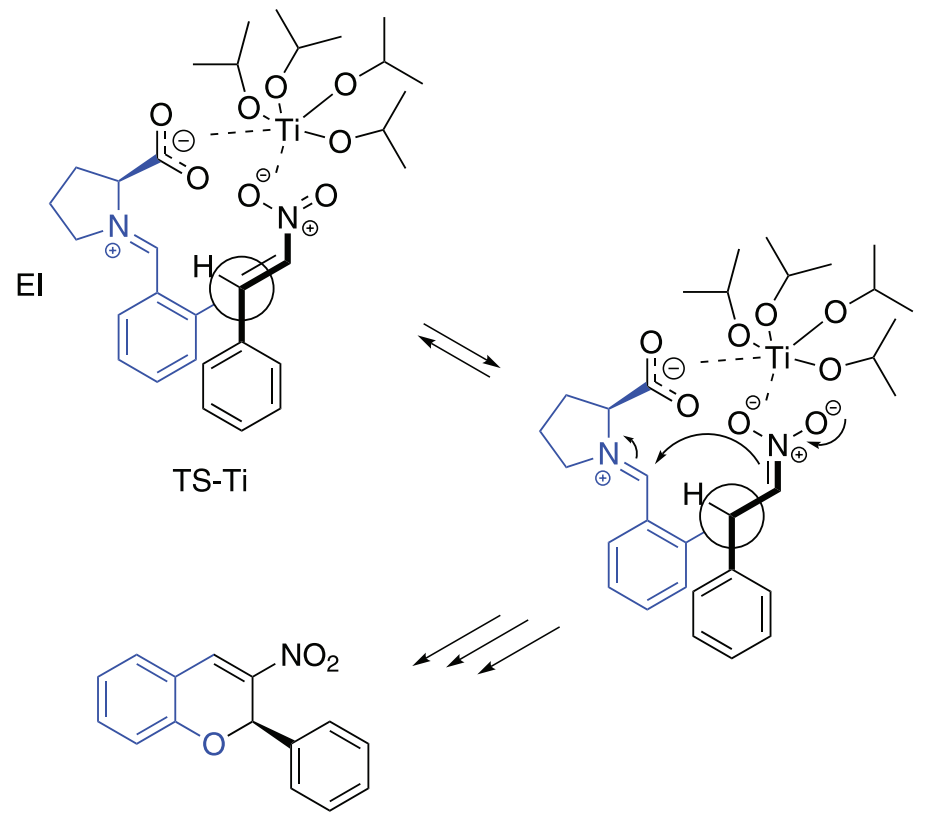

(R)-3-nitro-2-phenyl-2H-chromene

Figure 4. Representation of the $E$-iminium attack to the $\beta$-nitrostyrene face $S i$.

and $55 \%$ ee in catalytic conditions. The OXA-MichaelHenry reactions resulted on better yields when titanium was used as reagent and toluene as solvent. Thus, through screening with different co-catalysts, it was observed that the chiral environment is favored with the use of co-catalysts. Therefore, the work demonstrates that it is possible to obtain considerable enantiomeric excesses using an inexpensive and accessible amino acid.

\section{Supplementary Information}

Supporting information for this article is available free of charge at http://jbcs.sbq.org.br as PDF file.

\section{Acknowledgments}

We are grateful for the financial support from FAPEMIG (grant APQ-02400-14 to J. A. F. P. V.), CNPQ (476493/2013-7) and CAPES (fellowship to S. C. S. and L. F. C.). We also thank PPGMQ/RMQ.

\section{References}

1. Bulfield, D.; Huber, S. M.; Chem.-Eur. J. 2016, 22, 14434.

2. MacMillan, D. W. C.; Nature 2008, 455, 304.

3. Huang, W.; Anwar, S.; Chen, K.; Chem. Rec. 2017, 17, 363.

4. Amarante, G. W.; Coelho, F.; Quim. Nova 2009, 32, 469.

5. Stowe, G. N.; Janda, K. D.; Tetrahedron Lett. 2011, 52, 2085.

6. Hu, J.; Bian, M.; Ding, H.; Tetrahedron Lett. 2016, 57, 5519.
7. Zhao, K.; Zhi, Y.; Shu, T.; Valkonen, A.; Rissanen, K.; Enders, D.; Angew. Chem., Int. Ed. 2016, 55, 12104.

8. Wu, W.; Li, X.; Huang, H.; Yuan, X.; Lu, J.; Zhu, K., Ye, J.; Angew. Chem., Int. Ed. 2013, 52, 174.

9. Govender, T.; Hojabri, L.; Moghaddamb, F. M.; Arvidssona, P. I.; Tetrahedron: Asymmetry 2006, 17, 1763.

10. Feng, Y.; Luo, R.; Nie, L.; Wenga, J.; Lu, G.; Tetrahedron: Asymmetry 2014, 25, 523.

11. Pendalwar, S. S.; Chakrawar, A. V.; Bhusare, S. R.; Chin. Chem. Lett. 2018, 29, 942.

12. Li, H.; Wang, J.; E-Nunu, T.; Zu, L.; Jiang, W.; Wei, S.; Wang, W.; Chem. Commun. 2007, 507.

13. Luo, S.; Li, Z.; Wang, L.; Guo, Y.; Xia, A.; Xu, D.; Org. Biomol. Chem. 2009, 7, 4539.

14. Zhang, S.; Xie, H.; Zhu, J.; Li, H.; Zhang, Li, J.; Wang, W.; Nat. Commun. 2011, 2, 211.

15. Zhao, H.; Yang, Z.; Yue, Y.; Li, H.; Song, X.; Sheng, Z.; Meng, W.; Guo, X.; Synlett 2014, 25, 293.

16. Shen, H.; Yang, K.; Shi, Z.; Jiang, J.; Lai, G.; Xu, L.; Eur. J. Org. Chem. 2011, 5031.

17. Sund, H.; Ibrahem, I.; Zhao, G.; Eriksson, L.; Córdova, A.; Chem.-Eur. J. 2007, 13, 574.

18. Bhanja, C.; Jena, S.; Nayak, S.; Mohapatra, S.; Beilstein J. Org. Chem. 2012, 8, 1668.

19. Xu, D.; Wang, Y.; Luo, S.; Zhang, S.; Zhong, A.; Chen, H.; Xu, Z.; Adv. Synth. Catal. 2008, 350, 2610.

20. Karthikeyan, T.; Sankararaman, S.; Tetrahedron: Asymmetry 2008, 19, 2741.

21. Das, B. C.; Mohapatra, S.; Campbell, P. D.; Nayak, S.; Mahalingam, S. M.; Evans, T.; Tetrahedron Lett. 2010, 51, 2567. 
22. Zhang, Z.; Jakab, G.; Schreiner, P. R.; Synlett 2011, 9, 1262.

23. Yin, G.; Zhang, R.; Li, L.; Tian, J.; Chen, L.; J. Org. Chem. 2013, 24, 5431.

24. Sakakibara, T.; Koezuka, M.; Sudoh, R.; Bull. Chem. Soc. Jpn. 1978, 51, 3095.

25. Orue, A.; Uria, U.; Roca-López, D. I.; Delso, I.; Reyes, E.; Carrillo, L.; Merino, P.; Vicario, J. L.; Chem. Sci. 2017, 8, 2904.

26. Akai, J.; Watanabe, S.; Michikawa, K.; Harada, T.; Org. Lett. 2017, 19, 3632.
27. Gao, G.; Wang, Q.; Yu, X.; Xie, R.; Pu, L.; Angew. Chem., Int. Ed. 2006, 118, 128.

28. Torre, A. F.; Rivera, D. G.; Ferreira, M. A. B.; Corrêa, A. G.; Paixão, M. W.; J. Org. Chem. 2013, 78, 10221.

29. Wang, L.; Tang, R.; Yang, H.; J. Korean Chem. Soc. 2013, 57, 591.

Submitted: August 13, 2018 Published online: November 16, 2018 